\title{
How national curricula affect the design and transfer of a teaching-learning sequence between two educational systems: Case studies from Greece and Italy
}

\author{
Italo Testa ${ }^{*}$ \\ Department of Physics “E. Pancini,” University Federico II, Naples, 80136, Italy \\ Dimitris Psillos \\ School of Education, Aristotle University of Thessaloniki, Thessaloniki 54124, Greece \\ Anastasios Molohidis \\ Department of Physics, Aristotle University of Thessaloniki, Thessaloniki 54124 Greece
}

(Received 26 June 2019; accepted 2 December 2019; published 4 December 2020)

\begin{abstract}
This empirical study investigates the main features of curricula and contexts that favor or hinder the process of transfer of a teaching-learning sequence (TLS) from the designers' original situation to a host one. The specific research questions addressed were (RQ1) what were the changes made during the process of transfer in the new context? (RQ2) What were the similarities or differences between the national curricula and contexts that influenced the process of transfer? To answer our research questions, we chose two TLSs, one about optical properties of materials, the other about thermal conductivity, originally designed by two groups of researchers and experienced teachers in Italy and Greece, respectively. The transfer process was analyzed using the "adaptation and reinvention" model, originally developed for the management knowledge research field, while the construct of "institutional distance" was used to describe the influence of country-specific aspects on the transfer process. Data collected included background documents that describe the principles underlying the TLSs design, the decisions and changes made to the original TLSs by the hosting group, and reports on the TLS implementation in classroom practice in the original and in the host context. Content analysis was used to analyze data. Results show that the similarities between the two national curricula and interactions between the involved groups acted mainly as facilitators of the transfer process.
\end{abstract}

DOI: 10.1103/PhysRevPhysEducRes.16.020146

\section{INTRODUCTION}

Since the inception of the new century, European education policies have placed emphasis on knowledge transfer to promote students' motivation in learning science and to face issues related to a globalized and standardized system of instruction [1,2]. Therefore, the diffusion of science education results and the exchange of successful educational practices and artifacts have become relevant issues within the European Union. In particular, emphasis is on the dissemination of "best practices," namely, didactical interventions that were proved to be effective in the teaching practice of the country where they were developed. The idea of having different countries adopt the same effective didactical intervention is borrowed from the business and

*italo.testa@unina.it

Published by the American Physical Society under the terms of the Creative Commons Attribution 4.0 International license. Further distribution of this work must maintain attribution to the author(s) and the published article's title, journal citation, and DOI. management literature, which basically concerns how corporate organizations exchange successful home-markettested business models, experiences, and procedures from one country to another, in order to increase their profits $[3,4]$. When a best practice deals with the knowledge asset of an organization, the dissemination process is often known as "knowledge transfer" [5], defined by Szulanski [6] as the "replication of an internal practice that is performed in a superior way in some part of the organization and is deemed superior to internal practices and known alternatives outside the company." The first examples of knowledge transfer in the area of business and management, dating to the 1970s, concerned technological know-how and organizational routines $[7,8]$. The key factors that have to be taken into account for a successful knowledge transfer include the role of leadership, problem solving attitudes, supporting structures, and retentive capacity to negotiate and adopt new market strategies to implement in the host context [5]. Difficulties in the actual implementation of this process have been widely discussed in the management and business literature $[6,9,10]$. 
On the contrary, despite several research programs funded by the EU involved a knowledge transfer (e.g., inquiry-based science education) across different European countries, until now, very few studies have focused on the factors that could favour or hinder such process [11].

In this paper, we address this issue presenting in a narrative form the mutual interaction that took place during the transfer of two teaching-learning sequences (TLSs) about optical properties of materials and thermal conductivity, originally designed by two groups of researchers and experienced teachers located, respectively, in Italy and Greece. Drawing on the literature about management knowledge, specifically about the role played by similarities between the origin and host contexts, this study aimed to investigate to what extent similarities between educational systems of two countries have favored the transfer of the two TLSs, which had been proved to be successful in the original context. The specific research questions that guided this study are

(RQ1) what were the changes made during the process of transfer in the new context?

(RQ2) what were the similarities or differences between the national curricula and contexts that influenced the process of transfer of an original TLS to the new context?

\section{THEORETICAL FRAMEWORK}

\section{A. Teaching learning sequences}

One form of knowledge generation that has emerged as a fruitful research and development activity in science education refers to research-informed TLSs [12]. Teachinglearning sequences are structured teaching plans that go beyond the duration of isolated lessons in order to attain coherence in the learning objectives and activity sequencing, but do not reach high level specifications, such as national curricula. In this study, we define a TLS as a structured set of teaching materials involving the following: (i) a brief exposition of the relevant background knowledge; (ii) a review of the main findings of the corresponding science education research literature; (iii) a description of the pedagogical framework and the educational context; (iv) a set of stated learning objectives that are designed to promote coherent conceptual frameworks; (v) any prerequisite knowledge; (vi) a sequence of activities supported by any required teaching and learning materials or other teaching artifacts; and (vii) a set of formative assessment tasks that can be used to monitor student learning.

A key feature in the development of a TLS is that its design follows an iterative refinement process [13-16]. Typically, the adopted strategy consists in a repeated structure of a research-based "design" phase followed by an "implementation" phase, the results of which inform, by means of feedback and reflection analysis, successive "redesign" and "implementation" phases, resulting in successive refinements of the originally developed TLS. Each iteration contributes to refining didactical goals, improving teaching-learning activities, and gaining insights about students' understandings and the educational context in which the TLS is implemented.

Studies in the TLS tradition have been mostly focused on showing the effectiveness of a specific proposal in improving students' learning in the same educational context in which the authors work [17-19]. Only recently, the issue of the transfer of a TLS between two different educational contexts has gained some attention. In particular, the study by Spyrtou and colleagues [11] makes a first attempt to describe the transfer of a TLS about floating, sinking, and density, designed for the Greek educational context into the Finnish one. The authors show that three out of the four characteristics of the TLS (topic, pedagogical approach, modeling, use of computer-based simulations) were innovative for both countries. Moreover, they also show that students in both countries improved their conceptual knowledge about the chosen content. While providing valuable results, however, the study provides few insights about (i) the features of the educational contexts that favored the adoption of the TLS in the host country, and (ii) the changes made by the host group in order to favor the implementation of the TLS in their context. In the following section, we describe how we built on literature about knowledge transfer to address these issues.

\section{B. The knowledge transfer process}

As mentioned above, studies about the feasibility of knowledge transfer initiatives have been mainly carried out in the business management and organizational literature. In this area of research, knowledge is understood as a product, a policy, or practice in a given context (origin context). Knowledge transfer is defined as a process by which (i) one organizational unit (e.g., a group, department, or division) passes its experience to another (host context); (ii) systematically organized information and skills are exchanged between entities; (iii) knowledge is exchanged between or among individuals, teams, groups, or organizations [20].

Two models have been generally adopted to describe the transfer process from the origin to a host context [21]: the communication-based approach [6,22] and the knowledge creation model $[23,24]$. In the communication model, the transfer process consists of the encoding of a practice or knowledge through a suitable medium in order to favor the reception on behalf of the host context. In this model, the "adaptation" of the practice or knowledge to be transferred to the host context is unavoidable in order to improve the effectiveness of the process $[6,22,25,26]$. In this model, the context is not alterable due to local constraints. On the contrary, in the knowledge creation model, the transfer process implies a transformation of both the knowledge or 
practice to be transferred and the host context [27,28]. For instance, the host context may be subjected to modifications and changes to match the company's strategies to the market's needs.

The relevance of the context to investigate the success or failure of a transfer process is supported by studies in different research areas such as education [29] and health [30]. For instance, in a report about the transfer of a teambased learning approach in undergraduate medical education curriculum, Varpio and colleagues [31] found that local constraints such as the existence of language minorities led to alterations of the principles and philosophy at the basis of the approach. The authors concluded that the process of transferring the innovation of team-based learning lead to the transformation of the approach. Similar difficulties are reported by Kanu [32] about the transfer of a teacher education program, developed in Canada and the UK, to Pakistan: in this case study, three aspects, namely, the concept of self, discursive practice, and indigenous approach, acted as cultural barriers for the acceptance, on behalf of host teachers, of the "foreign" teaching methods.

Despite its relevance for the knowledge transfer process in educational research, in the above studies, the term "context" is not clearly and unambiguously defined. In some cases, the context concerns the individual level, and includes awareness, mindsets allegiances, behaviors, and personal accountability [33,34]. Other authors define the context in terms of the factors that influence the difficulty in transferring knowledge [6,9] or of the abilities and skills to be used to obtain an advantage or a profit from it [21]. Within this latest notion, Kostova [10] suggests three main types of contexts that affect the adoption of the practice to be transferred (p. 313): the social or institutional distance, defined in terms of the regulatory and normative practice, between the original and host settings; the organizational context, namely, the cultural and learning disposition as well as the compatibility of the practices; the relational context, namely, the attitude of the employee in the host setting toward the original setting.

\section{Adopted model of knowledge transfer}

To answer our research questions, we first adopted a working definition of context. Since learning in a socioconstructivist approach transcends the individual level, we conceptualized context as the social, institutional, and cultural settings that are involved in the transfer initiative [35]. Then, we had to choose a suitable theoretical framework for the knowledge transfer process. We excluded the knowledge creation model, mainly because we had no possibility to act upon the host educational contexts to force them in the adoption of the TLSs. Hence, we opted for the communication model. Our choice is supported by the empirical evidence in both business and science education research. As in the business and management area, some degree of adaptation unavoidably accompanies the cross-border transfer of firm-specific practices [36], so in science education, TLSs, in particular those aimed at innovating usual teaching habits, cannot simply be transferred from the original designers to the users (scholars, teachers, ...) but they are remade, reconstituted, and restructured [37]. In other words, the actions that will take place in order to adapt the original TLS, designed for the original educational context, to the host one in which it will be implemented, are unavoidably transformative. Our choice was also supported by the increasing interest of how such transformative actions, or simply transformations, impact the original curricular intervention [38]. Such interest has led to an increasing number of studies focusing on the construct of fidelity of implementation (FOI) [39-41].

The FOI is the counterpart of the "transformation" construct: when implementing a TLS in the host context, the more the fidelity to the original TLS, as intended by the original designers, the less the transformations that occur. Complementarily, the less the fidelity, the more the transformations that occur. Both FOI and transformations can be defined as the extent to which an innovation is implemented according to its original program design or as intended. However, how to measure FOI or the transformations enacted in a TLS implementation has been more difficult. In the literature about FOI, which mainly concerns curriculum studies, what is measured concerns the so-called fidelity to procedure, namely, the number, order, and alignment of methods in a curriculum $[42,43]$. Moreover, prior studies that used such a definition found no clear relationships between high FOI and students' learning gains. To justify such results, recently McNeill and colleagues [44] proposed a different conceptualization of FOI, focused on the goals of curriculum rather than the prescribed procedural elements of the curriculum. The authors support that the fidelity to goals may better interpret whether teachers' transformations of the proposed curriculum actually support students' learning. In particular, their results suggest a curriculum-in-use perspective, namely, that good teaching practices do not look identical in all classrooms and hence they cannot be generalized or transferred. While we do agree with McNeill and colleagues that "good teaching is responsive to the ideas and needs of the students", we also believe that a focus on solely the learning goals does not capture the complex nature of a TLS, which also involves specific procedures (e.g., a laboratory experiment or a simulation) and specific educational artifacts (e.g., laboratory worksheets, written tasks) to be used to help students learn the addressed topic.

To consider the complexity embedded in the TLS transfer process, we framed this study into a specific communication model, namely, the "adaptation and reinvention" (ARI) model [45]. Within this model, a basic transfer process consists of a bidirectional communication between two contexts, the first being that of the original 


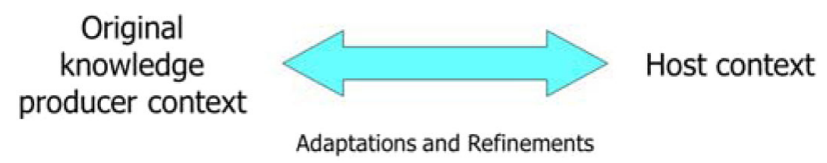

FIG. 1. Graphical representation of the basic adaptation and reinvention model [45].

knowledge producer, the second the host context. During the communication process, a consensus about the adaptations and refinements that the original product must undergo in order to fit the host context should be reached (Fig. 1).

In the case of a TLS transfer, we conceive the transfer process as an interactive cycle consisting of a decontextualization of the original implementation procedures, the identification and adaptation of general "core" elements embedded in a TLS, and a recontextualization of these elements in the new setting (Fig. 2).

The core elements include the conceptual sequence of addressed contents, the learning goals, and the pedagogical procedures of a TLS [14] and can be related to, e.g., inquiry, modeling, argumentation, informationcommunication technologies (ICT), or any other aspects of the teaching activities that are considered important by the original designer. Of course, not all elements of a TLS are core elements: for instance, some specific activities or particular experiments cannot be included in the core, unless they are considered essential for the conceptual sequence of the overall TLS. For the aims of this study, the original TLS was therefore judged transferable if the changes proposed and agreed between the two groups (designers and host) during the whole process did not affect radically the core elements of the TLS.

\section{Implementation of the ARI model}

The ARI model enacts a more interactive relationship between the knowledge designer and the host context than traditional communication models of knowledge transfer. In our study, the designer and host were two research

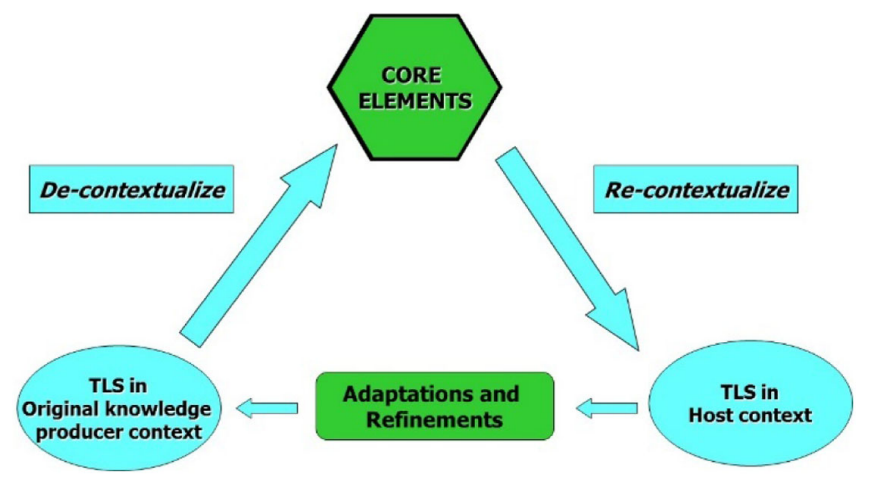

FIG. 2. Graphical representation of the modified ARI model to frame TLS transfer process. groups in two universities, one located in Greece, the other in Italy. The relationship between original and host groups was implemented as a mutual research collaboration carried out during three years around the issue of facilitating the cross-national transfer of two TLSs developed by the two groups. This interaction process led to a mutual understanding of shared knowledge where both groups reciprocally gained new insights. The collaborative relationship was implemented as follows.

The original designers and host groups formed what we called a local working group (LWG). Each group included science education researchers, content experts, and inservice teachers. The aim of forming a LWG was to facilitate the distribution of expertise on teaching and learning processes, instructional design and classroom implementation. The main task of the LWG was to design a TLS on a given science content. After the creation of pairs of LWGs in the consortium, each designer LWG organized a classroom implementation of the TLS to evaluate the feasibility of the TLS activities and to document students' learning outcomes. During this class implementation, two persons of the host LWG and one external "expert" in science education research participated in what we called a "peer study visit." The aims of the visit were to offer a short-track feedback to the LWG about the design, implementation, and evaluation through teacher's and students' actions and interaction of the TLS and to facilitate the transfer of the original TLS into the host context by enhancing the communication and interaction between the two partner LWGs, according to research results in literature about technological know-how transfer [46]. Data collected during the visit included experts' observation notes, interviews with local teachers and students, and notes on discussions between researchers and the external expert. The original designer partner, before the visit, provided the persons of the host LWG and the external expert with a background document, aimed at communicating the rationale of the TLS, the process of design and validation of the TLS, and preliminary results about students' learning. More specifically, this document included, in concise form the formal scientific knowledge underlying the teaching activities; detailed information about the design of the TLS, namely, the design principles, the pedagogical approach, the methodological framework, the student assessment tools, and suggested procedures to implement the TLS; information about national educational context and specific school settings in which the TLS had been tested; the relevance of TLS for the local national curriculum; and recommendations for implementing the TLS in another educational setting away from its development context. Overall, emphasis in the background document was placed on the design and development of the TLS, namely, the iterative cycle of refinements and improvements of the activities, as well as on the contextual information necessary to the visiting experts to make sense 
of the educational system for which the TLS was developed. If some parts of the document were not clear, emails were exchanged between the two LWGs to clarify emergent issues. Moreover, the designer LWG asked details about expert's professional profile, highlighting expectations and the specific points on which to receive and exchange information. After the visit, a report written by the two persons of the host LWG and the external expert summarized the results of the visit. Within this report, comments and reflections about critical issues of the observed TLS were provided to the original designers. These steps completed phase I.

Then, the host local working groups began the process of adapting the original TLS by abstracting the core elements and decoding the underlying pedagogical orientations through the ARI model. The process was enacted through mutual virtual interactions between the two LWGs. The aim of this phase was to design a "new" version of the TLS, adapted to the host educational context to take into account cultural aspects and organizational constraints of the host educational context. Adaptations were implemented also according to the beliefs, values, and convictions about teaching and learning processes (epistemologies) of the host LWG. The adapted version of the TLS was then implemented in the host context to collect data and to validate the TLS according to local purposes. During this implementation, a second peer study visit took place, involving two members of the designer LWG and the same external expert who participated in the first visit. The aim was to provide a kind of feedback to the host LWG on the extent to which the adapted TLS adhered to the design principles of the original TLS. The host partner, before the visit, prepared a new background document, aimed at communicating the rationale of the changes carried out to adapt the TLS, the validation of the TLS, and preliminary results about students' learning. The most important part of this new background document was the description of the host educational context, including local national curriculum guidelines and the specific school settings in which the TLS would have been implemented. Again, email exchanges occurred between the two LWGs to clarify emergent issues. During the visit, the same kind of data as the first visit were collected. After the visit, a second report was written by the two persons of the designer LWG and the external expert to summarize the results of the visit. In particular, this document included remarks about the feasibility of the TLS implementation in the host educational context and about the effectiveness of the introduced changes. The host LWG, on the basis of this report, designed a revised version of the adapted TLS. These steps completed phase II of the process. Overall, this model of collaborative interaction allowed the negotiation and renegotiation of beliefs, convictions and values concerning instructional design of the two LWGs, and the mutual learning of similarities and differences between the educational systems to which the groups belonged.

\section{METHODS}

\section{A. Description of the Greek and Italian educational contexts}

In this section, we describe the national educational context for which the Greek and Italian TLSs were developed. The TLS addressed thermal and optical properties of materials, respectively.

The Greek educational context.-The Greek TLS was designed for the lower secondary school, called gymnasium, which is compulsory and addresses $12-15$ years old students. Physics is an individual subject taught in the second and third grade and to 13-15 years old students for $2 \mathrm{~h}$ per week. In most schools, science teaching is based on the traditional transmission model, focusing on declarative knowledge and including some demonstrations and minimal, if any, experimental work. One of the chapters in the year two gymnasium physics textbook concerns "heat and temperature," addressing these concepts at macroscopic and microscopic levels. Heat transfer is also addressed, dealing rather superficially with the microscopic processes underlying heat exchanges. While curriculum implementation is strictly scheduled, special arrangements allow teachers to pursue an in-depth treatment of disciplinary and interdisciplinary themes, like conductivity, using extracurricular materials, in a "flexible zone" part of the school timetable of about $2 \mathrm{~h}$ per week.

The Italian educational context.-The Italian TLS was designed for first-year technical school students (about 14-15 years old). Technical school is a secondary school stream which refers to the EU normative about vocational education and training. In this stream, the pedagogical approach is that of integrated sciences with emphasis on compulsory laboratory activities. There are two main types of technical schools, focused, respectively, on economics and technology. In the economics-oriented technical school, the focus can be on marketing, finances, and administration or tourism. The technology-oriented technical schools are subdivided into 9 streams: mechanics; transportation; electronics; informatics and telecommunication; graphics and communication; chemistry, materials, and biotechnology; fashion; agroeconomics; environment and territory. The TLS was, in particular, developed for students of the electronics strand. The aim of this strand is to develop skills related to science and technology. This strand has also a specific focus on the design of materials and the study of their properties aimed to build up electric and electronic systems used in telecommunication. Optics is taught by the physics teacher. In particular, the syllabus addresses in detail geometrics optics, reflection, and refraction laws. 


\section{B. Description of the TLSs}

In this section, we describe in more details the TLSs that the two local working groups transferred between their respective educational contexts, described above. The "educational reconstruction" model $[47,48]$ was used as a common theoretical framework to design the TLSs. More details are reported in the Supplemental Material [49] and in Refs. [16,50].

\section{The TLS about thermal properties of materials}

The Greek teaching-learning sequence is aimed at the understanding of scientific concepts and models related to heat conduction and thermal conductivity. In particular, the learning objectives are to identify the factors that affect thermal conductivity of materials, to distinguish between conductors and insulators, and to become familiar with models and microscopic processes for thermal conductivity in ceramics and metals. During the activities, the students collect evidence to qualitatively relate the rate of heat transfer to material's type, exchange surface extension, border thickness. Applications to problematic real-life situations (namely, the warming of a house) are also discussed.

From the pedagogical viewpoint, in designing the TLS, we considered that teaching science as inquiry requires to shift from a teacher-centered instruction to a more learnercentered approach, which should aim at improving students' epistemological awareness and investigative skills as well as conceptual achievement. Hence, the proposed teaching units are based on the predict-observe-explain (POE) strategy [51] and are aimed at familiarizing students with scientific inquiry, specially improving their capability to design experimental investigations, to verify or reject a hypothesis, and to become familiar with microscopic models to interpret macroscopic properties. An information communication technologies (ICT) enriched learning environment is created to exploit didactically reconstructed microscopic representations that depict thermal interactions in iconic, graphic, and symbolic forms. Microscopic visualizations of conductivity for different materials are provided so to address the effect of density, of free electrons, and of air inclusions on conductivity of different materials. During the TLS activities, students work in groups, solve problems, and are engaged in classroom discussions with the aim of constructing links between evidence and explanations. The TLS was implemented in the Greek context with overall 140 13-14 years old students in three different implementations. Evidence from each implementation refined the TLS. Results from the third iteration of the TLS show remarkable progression in conceptual domain (about 92\% acceptable explanations), in the epistemological domain (e.g., about $60 \%$ of the students considered that the model is "a way to understand a phenomenon and not a replica of a phenomenon," while in the pretest, only $20 \%$ of them held this idea) and in the procedural domain (e.g., for the dimension "control of variables," $80 \%$ of the students gave acceptable answers). More details are available in Refs. [15,50]. In the Supplemental Material A1 [49], we report the relevant science education literature that informed the Greek TLS.

\section{The TLS about optical properties of materials}

The Italian TLS is aimed at making learners understand optical fibers and their properties, starting from the key idea of how and why light can be guided [52]. In particular, the main scientific concepts addressed are (i) light pathway in a (optically) homogeneous medium and at the interface between two media, and (ii) reflection and refraction, total internal reflection. The TLS features hands-on experimental investigations with lasers and water tanks inspired to a guided inquiry approach with the aim to support active students' engagement, collaborative learning, and sharing of conclusions drawn from available evidence. The students investigate unfamiliar problems related to the behavior of the optical fiber guided by the teacher which encourages them to express their ideas, to formulate hypotheses, and to reflect on the initial scenario. To investigate in a more quantitative way how optical properties come into play when light interacts with diverse materials, the experiments are integrated with measurements and simulation tasks designed with Cabrì II Plus [53]. The TLS was implemented in the Italian context with about 100 students in three different implementations. Results from the pre- and postinstruction questionnaires and interviews show that about $75 \%$ of students correctly understood the role of the refraction index and total internal reflection in the functioning of optical fibers. Similar positive results emerged about students' understanding of propagation of light and total reflection in optical fibers (about 70\% of correct answers). More details are reported in Refs. [16,52]. In the Supplemental Material [49] A2, we report the relevant science education literature that informed the Italian TLS.

\section{Transfer contexts of the TLSs}

\section{Transfer of the Greek TLS into the Italy context}

The Greek TLS was adapted for students of the first year of technical schools (14-15 years old). The main reason for this choice of school was to maintain about the same target student age as in the Greek context, since, at the time of implementation, students of that age range were taught some basic aspects concerning heat and temperature phenomenology, heat conduction, and some aspects of matter structure (namely, atoms and molecules) only in technical schools. Another reason for the choice of the type of school was that, in the Italian educational system, laboratory activities were compulsory only for this kind of school. Moreover, in all other secondary school streams, the above themes were treated later (students' age about 16). In the physics syllabus of the first year of technical schools, topics such as heat and temperature are addressed in some 
detail, including formalization of the basic relationship $\Delta Q=m c \Delta T$, but the study of thermal conduction is often limited only to the distinction between conductors and insulator. In very nonfrequent cases, a formalization of the Fourier law is given without any theoretical demonstration; very seldom, the law is verified by means of demonstration laboratory activities. Most importantly, the relationships between macroscopic phenomena and behavior of matter at a microscopic level are never addressed. The specific school where the TLS implementation took place was a public school located in the same town as the Italy local working group. The school receives students mainly from suburbs, characterized by a high grade of social hassle and underemployment problems. Two intact classes were involved in the implementation. Both classes were constituted by about 20 students. The teachers who implemented the TLS were both experienced, with a long collaboration with the LWG. During the study visit, the Greek observers and the external expert could attend three school sessions (total $5 \mathrm{~h}$ ), to have short interviews with four students, and to interview the two teachers (T1 and T2) who implemented the TLS. In the first observation (Teacher T1), 10 students worked at the macroscopic model of temperature. In the second-class observation (Teacher T2), 14 students of a different class performed the basic hands-on experiments of heat conduction proposed in the original TLS. In the thirdclass observation, Teacher $\mathrm{T} 2$ worked at the microscopic model with about 10 students. In Supplemental Material B [49] we report the complete outline of the Greek TLS as adapted by the Italian LWG. In Supplemental Material C1, we describe an emblematic activity of the adapted Greek TLS. In Supplemental Material D1, we report the assessment tools used to investigate the effectiveness of the Greek TLS.

\section{Transfer of the Italian TLS into the Greece context}

The Italian TLS was adapted for the third grade of the lower secondary school (grade 9, about 13-14 year-old students, the end of compulsory schooling in Greece after 6 years of primary and 3 years of secondary education). The reason for choosing such target is that in the physics syllabus for 9th graders, optics includes light phenomena such as reflection, refraction, and analysis of light, addressed in the Italian TLS. Light is regarded as energy transfer according to particle theory (photons), which is used to explain the absorption of light. Additionally, for the investigation of reflection and refraction phenomena, the ray model and Fermat's principle of least time are introduced. Since the curriculum in Greece is compulsory, the room left for changes of activity sequence is very limited. For this reason, the sessions took place in a private school in the urban area where the Greek local working group was situated. The school followed the official national curriculum yet some flexibility on applying innovative approaches was tolerated. In particular, teaching is normally carried out in a traditional way, but some laboratory activities are also performed. Two sessions were observed by two members of the Italy LWG and the external expert. Twenty-four students were involved in this implementation. In the first observation by the visiting experts, the students worked in a physics laboratory and performed the experiment with the water tank and the laser. The day after, the students worked, in the informatics laboratory, on light refraction using the Cabrì software. Before the implementation the pupils had familiarized with Cabrì for about $2 \mathrm{~h}$. After the second session, the visiting experts had short interviews with four of the involved students and with the teacher who implemented the TLS. In Supplemental Material B [49] we summarize the Italian TLS adapted by the Greek LWG. In Supplemental Material C2 an emblematic activity of the adapted TLS is reported. In Supplemental Material D2 we summarize the assessment tools designed for the adapted Italian TLS.

\section{Data collection}

We documented the transfer process with multiple sources of data, namely, "field texts" [54] collected during the three-year collaboration between the two research groups involved in the transfer process. The first type of field text was the background document prepared and provided to the host partner by the original developer of the TLSs just before the first peer study visit (see Supplemental Material E [49]). The second type of field text were the emails exchanged between the two groups in internet-based communication, aimed at enhancing interactions and mutual understanding of the two TLSs. The third type of field text was the new background document prepared by the host partner and sent to the original developers before the second study visit (see Supplemental Material F [49]). The fourth set of field text consisted of the study reports that, after each peer study visit, the visiting experts prepared on the basis of the data collected during the implementation in the host context (see Supplemental Material G [49]).

\section{E. Data analysis}

We used a multiple case study approach [55] to answer our research questions. The aim was to look back "in retrospect" at the different phases carried out during the transfer process to provide meaningful insights about the implemented mechanism. Content analysis [56,57] was used as research method. The reason for choosing content analysis is that it aims at making valid inferences from text data [56]. In particular, the in retrospect content analysis of the data collected during the interactions that took place during the transfer process allowed us to investigate if the core elements of the original TLS have been modified, kept, or removed during the recontextualization phase of the transfer as implemented with the modified ARI model.

Analysis of collected data went through two steps, represented in Fig. 3. In the first step, we initially 


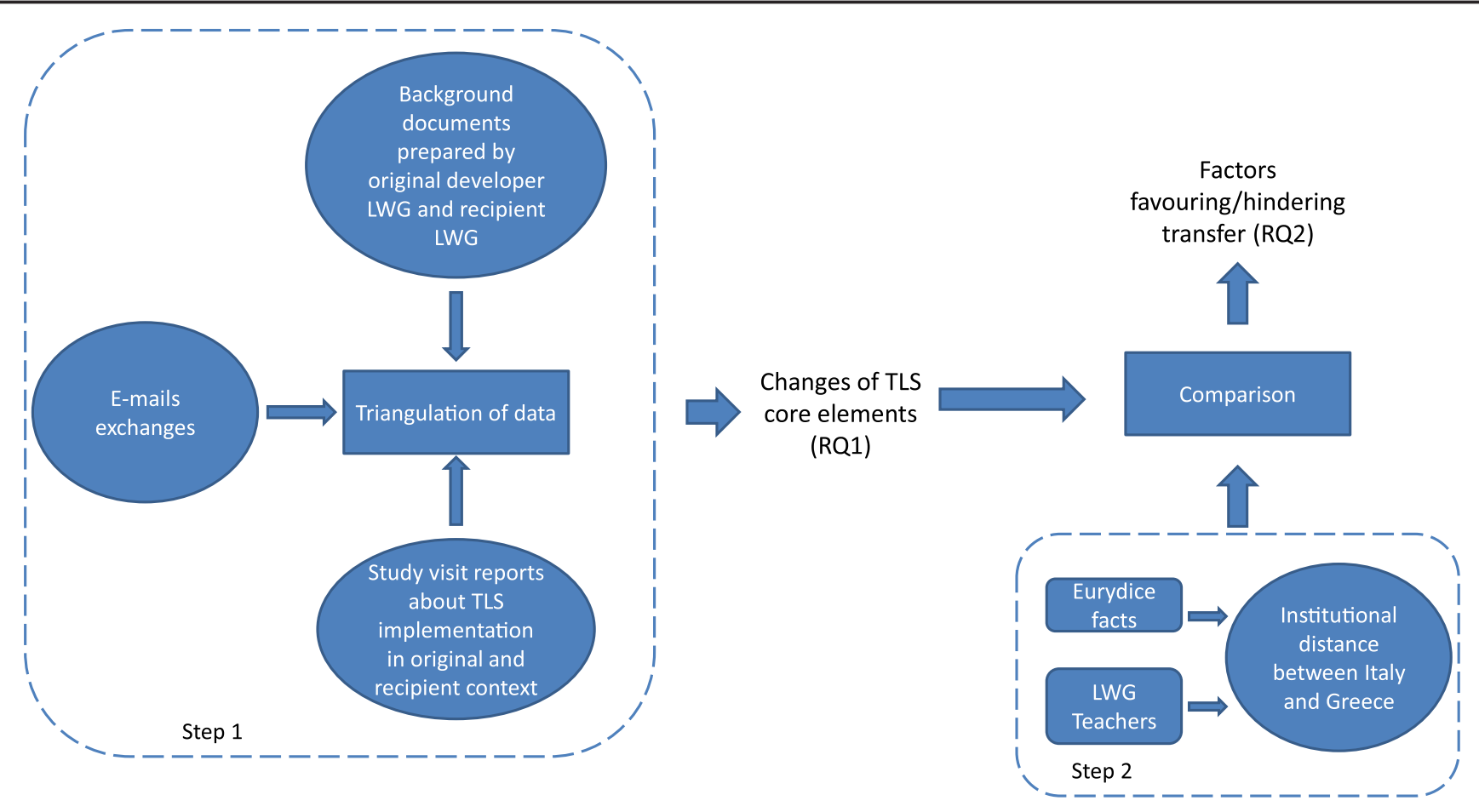

FIG. 3. Schema of data analysis.

performed a directed content analysis [57] of the background documents prepared by the original TLS developer and the host partner. The directed content analysis can be used when the choice of categories is theoretically driven. More specifically, using the ARI model, we first constructed a table of the core elements that could be extracted from the background documents provided by the original developers to the host partner and, then, we listed the adaptations described in the background document provided by the host partner to the original developers. Second, the results of the analysis of the background documents were triangulated with the evidence from the reports about the two peer study visits implemented in the original and host context. The procedure was carried out for each TLS. The comparison process was iterated twice, and results reviewed by all authors with the aim of finding cross evidence of the core elements and the performed changes. Finally, the email exchanges aimed at requesting clarification of certain points of the background documents were used to refine and strengthen the analysis. Only evidence that was consistent among all the field texts was retained. Such retrospective analysis allowed us to reconstruct the "story" of the whole process of transfer and to identify the changes made by the host partner to fit the TLSs in the new educational context, as well as the extent to which these changes affected the "core" elements of the TLSs (RQ1).

In the second step, we attempted to identify the similarities and differences between Italy and Greece educational contexts. To this aim, we used the construct of institutional distance developed in the international business and organization research field [10] to describe the influence of country-specific aspects on international marketing strategies of firms and multinational corporations [58-61]. The construct is defined by three dimensions: regulatory, cognitive, and normative. The regulatory dimension consists of rules and regulations, how they are monitored and the extent to which they are applied in practice. The cognitive dimension includes frames, routines, and scripts used by individuals to judge and to assign meaning to a phenomenon and to solve problems. More specifically, this dimension includes how persons perceive and interpret stimuli from the social environment $[62,63]$. Finally, the normative dimension refers to what is preferred or desirable (values), and to how things should be done (norms) and therefore delineate what a society perceives as an accepted behavior [64].

Then, we had to adapt these dimensions to our specific case of the transfer of educational innovations. Since we found no reference in educational literature about institutional distance, we resorted to what could be considered as a proxy for this construct. The two groups engaged in email discussions to share a list of features that could be relevant for the three dimensions in an educational context. The proxy construct consisted initially in an adaptation and redefinition of the three dimensions in the educational context. By extension of the original definitions of the dimensions, the two groups agreed upon the following definitions: the regulatory dimensions refers to the existence of a national school curriculum, to how the curriculum prescriptions impact the teaching practice and the school 
TABLE I. Features used to estimate the institutional distance between Italian and Greek educational contexts.

\begin{tabular}{|c|c|c|}
\hline Dimension & Feature & Range of variability \\
\hline Regulatory & $\begin{array}{l}\text { 1. Degree of freedom left to teachers to deviate from } \\
\text { national curriculum. } \\
\text { 2. Degree of integration across science and } \\
\text { technology subjects. } \\
\text { 3. Degree of integration across science subjects. } \\
\text { 4. Sequence of contents. } \\
\text { 5. Use of standardized tests. }\end{array}$ & $\begin{array}{l}\text { Substantial-moderate-scarce } \\
\text { Mostly separated-partly integrated-integrated } \\
\text { Mostly separated-partly integrated-integrated } \\
\text { Mandatory-suggested-free } \\
\text { Yes-partly-no }\end{array}$ \\
\hline Cognitive & $\begin{array}{l}\text { 6. Implementation of inquiry-based methods and } \\
\text { student-centered approaches. } \\
\text { 7. Use of computer-based activities. } \\
\text { 8. Use of laboratory-based activities. } \\
\text { 9. Use of modeling approach. } \\
\text { 10. Use of textbooks. }\end{array}$ & $\begin{array}{l}\text { Very diffused-partly diffused-scarcely diffused } \\
\text { Frequent-partly frequent-not frequent } \\
\text { Frequent-partly frequent-not frequent } \\
\text { Frequent-partly frequent-not frequent } \\
\text { Frequent-partly frequent-not frequent }\end{array}$ \\
\hline Normative & $\begin{array}{l}\text { 11. Teachers' beliefs about teaching and learning } \\
\text { science. } \\
\text { 12. Teachers' views about the goals of school science } \\
\text { education. } \\
\text { 13. Teachers' views about the role of ICT in teaching } \\
\text { and learning science. } \\
\text { 14. Teachers' views about the role of laboratory } \\
\text { activities in teaching and learning science. } \\
\text { 15. Teachers' views about nature of science (NOS) } \\
\text { and nature of scientific inquiry (NOSI). }\end{array}$ & $\begin{array}{l}\text { Traditional-process-constructivist } \\
\text { Train future scientists-give students basic ideas/facts of } \\
\text { science-familiarize most of the students with science } \\
\text { To barely support to lesson-to simulate experiments-to } \\
\text { improve students' experimental skills } \\
\text { Confirmatory-to deduce laws and models-authentic practice } \\
\text { Empiricism-rationalism-progress }\end{array}$ \\
\hline
\end{tabular}

subjects' regulations; the cognitive dimension refers to prevalent and most often diffused practices enacted by teachers to improve students' learning; the normative dimension prevalently refers to teachers' beliefs, values, and social norms implemented in school practice. It was hence decided to construct a list of features that could capture the essence of the three dimensions. After two rounds of email discussions, a list with 15 features relevant for the transfer of the TLSs with a three-level scale of variability was finalized (Table I). Once the list was finalized, the two groups independently rated the extent to which each feature of the three dimensions was applicable in their home country using the three-level scale. The information to rate the features were retrieved mainly from the Eurydice website and from the teachers that participated to the local working group. Then, the ratings given to the features in the two contexts were compared and a score was assigned to each comparison: 1 , if the rating was the same for the two contexts, 0 if the rating differed. Finally, the frequency of 1 ratings was summed up and divided for the total number of features of each dimension obtaining what we called the intercountry index. This three-dimensional index was used to establish the institutional distance between the two educational contexts. To evaluate the resulting distance, we used criteria similar to those exploited in the interrater reliability procedure (Table II). Finally, data from the first step were compared with the data from the second step to infer possible factors related to the specific host school contexts that actually impacted on the transfer of the TLSs (RQ2).

\section{FINDINGS}

\section{A. Changes made during the process of transfer}

The content analysis of the background documents provided by the original designers to the host partner evidenced the "core elements" of the two TLSs (Table III). The two TLSs look quite different according to the chosen core elements. In the pedagogical approach, the Greek TLS features a guided inquiry approach, which exploits the POE strategy, and structured worksheets, whereas the Italian TLS features more open activities. Some differences in the implementation of scientific inquiry also emerge. In particular, the inquiry activities proposed by the Greek TLS focus more on the design of

TABLE II. Criteria used to estimate distance between Italian and Greek educational context.

\begin{tabular}{lc}
\hline \hline Intercountry index & Distance \\
\hline $0.00-0.20$ & Great \\
$0.21-0.40$ & Substantial \\
$0.41-0.60$ & Medium \\
$0.61-0.80$ & Moderate \\
$0.81-1.00$ & Short \\
\hline \hline
\end{tabular}


TABLE III. Core elements of the original teaching-learning sequences.

\begin{tabular}{|c|c|c|}
\hline Core element & TLS about thermal conductivity & TLS about optical properties of materials \\
\hline $\begin{array}{l}\text { Pedagogical } \\
\text { approach }\end{array}$ & $\begin{array}{l}\text { Guided observation with application of POE strategy } \\
\text { design of experiments. }\end{array}$ & Open investigations \\
\hline $\begin{array}{l}\text { Scientific } \\
\text { inquiry }\end{array}$ & $\begin{array}{l}\text { Guided exploration by students of provided microscopic } \\
\text { reconstructed models. Design of experiments and } \\
\text { experimentation with variables surface and width. } \\
\text { Metacognitive reflections within units and overall } \\
\text { guided investigation at the end of the TLS. }\end{array}$ & $\begin{array}{l}\text { The students are asked how it is possible to guide the } \\
\text { light; then, they are encouraged to express their ideas } \\
\text { about the problem and to design an experiment with } \\
\text { lasers and water tanks to test their hypotheses. }\end{array}$ \\
\hline Modeling & $\begin{array}{l}\text { Exploratory use by students of simulated microscopic } \\
\text { teaching models for visualizing and interpreting } \\
\text { temperature and thermal conductivity. Engagement of } \\
\text { students to guided exploratory modeling activities and } \\
\text { reflections on the nature function and scope of } \\
\text { scientific models. }\end{array}$ & $\begin{array}{l}\text { Descriptive modeling inspired to a rationale } \\
\text { implemented through the following steps: Observe a } \\
\text { complex phenomenon of light propagation, perform } \\
\text { experiments, and give a first interpretation of what has } \\
\text { been observed. Import a photo of the experiment in the } \\
\text { Cabrì modeling environment in order to recognize } \\
\text { regularities. Formalize the regularities in the refraction } \\
\text { and reflection laws. }\end{array}$ \\
\hline $\begin{array}{l}\text { Scientific } \\
\text { concepts }\end{array}$ & $\begin{array}{l}\text { Heat and temperature, heat conduction in materials, } \\
\text { behavior of thermal insulators and conductors } \\
\text { (ceramics and metals), microscopic model of matter. }\end{array}$ & $\begin{array}{l}\text { Reflection and refraction, index of refraction, total } \\
\text { internal reflection. }\end{array}$ \\
\hline ICT & $\begin{array}{l}\text { Use of simulated microscopic models of temperature } \\
\text { change and thermal conduction in ceramics and } \\
\text { metals. Use of a virtual laboratory and simulated flash- } \\
\text { based experiments. }\end{array}$ & $\begin{array}{l}\text { Cabrì simulations and measurements. The idea is to start } \\
\text { with a kind of "Data Fitting" processing digital photos } \\
\text { in the Cabrì environment, by identifying the best } \\
\text { straight lines that describe the light path. Later, } \\
\text { animated simulations of light paths in various media } \\
\text { allow a virtual exploration of how variations in some } \\
\text { parameters affect the light behavior. }\end{array}$ \\
\hline Other aspects & $\begin{array}{l}\text { Combination of virtual and hands-on experiments. Use } \\
\text { of exemplar experiments on thermal conduction in } \\
\text { metals. Interplay of macro- with microprocesses, } \\
\text { conductivity in containers, and bars. Thermal } \\
\text { insulation of a house as application. }\end{array}$ & $\begin{array}{l}\text { Optical fibers use in everyday life scenario at the } \\
\text { beginning. Focus on the relations between science and } \\
\text { technology. }\end{array}$ \\
\hline
\end{tabular}

experiments approach, whereas those by the Italian local working group are more focused on eliciting students' ideas to solve the (technological) problem of guiding the light along predefined paths. Also, the chosen modeling approach is different, since the Greek TLS privileges an interpretative and exploratory modeling approach whereas the Italian TLS is more focused on a descriptive approach that leads to a mathematical formalization of the observed phenomena. Both TLSs include meaningful ICT activities to enhance the student's engagement and conceptual understanding of the addressed topics. The main difference between the two TLSs is that the Italian TLS starts from a technological scenario whereas the Greek TLS presents the house insulation as a final guided investigation and employment of the learned concepts. The design choices were probably linked to different science education epistemologies (beliefs, values, and convictions) of the two research groups as well as to different approaches to research-based design of innovative teaching materials.
Such differences also informed the changes proposed to the original TLSs (see Tables IV and V).

\section{B. Similarities and differences between the Greek and Italian contexts}

Table VI summarizes the ratings given to the features of the model dimensions in the two contexts and the score assigned to each contrast. The distance was substantial in the regulatory dimension, short in the cognitive dimension, and moderate in normative one. In the regulatory dimension, the organization of the Greek and Italian curricula is similar only for the organization of the school subject. The Greek curriculum treats scientific and technological knowledge as distinct subjects in all three grades of the lower secondary school (7th to 9th grade). Scientific concepts are usually introduced in the subjects of sciences (physics, biology, chemistry), while technology is treated as a distinct subject which is usually taught by science or engineering teachers and focuses mostly on developing 
TABLE IV. Changes to the core elements of the transferred TLS on thermal conductivity.

\begin{tabular}{lll}
\hline \hline Core element & \multicolumn{1}{c}{ Description of the changes } & Justification \\
\hline Modeling & $\begin{array}{c}\text { Additional use of mechanical analogy to justify particle } \\
\text { interactions in ceramics and metals } \\
\text { Quantitative relationship among the factors influencing } \\
\text { thermal conduction. }\end{array}$ & $\begin{array}{c}\text { To facilitate students' interpretation of the heat transfer } \\
\text { mechanism } \\
\text { The formalization seemed necessary because Italian } \\
\text { textbooks at the lower secondary school level } \\
\text { usually formalize physics laws in a mathematical } \\
\text { way. Moreover, it is usual to collect experimental } \\
\text { data to prove studied laws. }\end{array}$ \\
$\begin{array}{c}\text { Other aspects } \\
\text { Changes in the conceptual sequence, e.g., (a) problematic } \\
\text { situation about house insulation addressed at the } \\
\text { beginning of TLS; (b) introduction of all factors } \\
\text { affecting heat conduction before microscopic model. }\end{array}$ & $\begin{array}{l}\text { (a) House insulation can be motivating for students } \\
\text { and a unifying thread for all the proposed activities; } \\
\text { (b) improving the understanding of macroscopic } \\
\text { behavior may allow for a better justification of the } \\
\text { microscopic interpretation }\end{array}$ \\
\hline \hline
\end{tabular}

artifacts. Science and technology are two distinct subjects at middle school level and secondary school level also in the Italian curriculum. However, other features are different: for instance, in the Greek curriculum, the sequence of concepts is almost mandatory, while Italian teachers have the possibility to change the suggested sequence. In the specific case of the teaching of optics, in the Greek curriculum, Fermat's principle of least time and the ray model must be introduced for interpreting optical phenomena such as reflection and refraction. Techno-objects like optical fibers should be introduced as applications of scientific knowledge. On the contrary, in the Italian curriculum, the sequence is only suggested. Light is addressed first by presenting the wave-particle duality, then the ray model can be introduced. However, as in the Greek curriculum, optical fibers are taught as applications of geometrical optics laws. After a discussion about light sources and rectilinear propagation, the reflection and refraction laws are qualitatively addressed. Some applications of the total reflection, as optical fibers, can briefly be described. The Italian group clarified in the email discussions that the higher level of freedom in choosing the sequence of concepts was introduced in the national curricula by political school reforms that were implemented in recent years in Italy.

Quite the reverse, the cognitive and normative dimensions revealed a short or moderate institutional distance between Italy and Greece (above 0.8). Thus, teaching practices and teachers' attitudes about science were then considered very similar in the two contexts.

TABLE V. Changes to the core elements of the transferred TLS on optical properties of materials.

\begin{tabular}{|c|c|c|}
\hline Core element & Description of the changes & Justification \\
\hline Modeling & $\begin{array}{l}\text { Introduction of interpretative models of light refraction } \\
\text { (ray model, Fermat principle). }\end{array}$ & $\begin{array}{l}\text { To facilitate the interpretation of the phenomena and } \\
\text { increase students' awareness of the interpretive role } \\
\text { of models and of the purpose of scientific models } \\
\text { and modeling. }\end{array}$ \\
\hline \multirow[t]{2}{*}{$\begin{array}{l}\text { Pedagogical } \\
\text { approach } \\
\text { Scientific } \\
\text { concepts }\end{array}$} & $\begin{array}{l}\text { Introduction of the POE strategy and requests for } \\
\text { metacognitive reflections on the activities Inversion } \\
\text { of the teaching sequence: reflection before } \\
\text { refraction. }\end{array}$ & $\begin{array}{l}\text { To enhance students' engagement in the activities and } \\
\text { provide them with a tool for a self-evaluation of their } \\
\text { learning pathway. To introduce measurement theory } \\
\text { by comparing quantities that should have the same } \\
\text { value (incidence and reflection angles). }\end{array}$ \\
\hline & $\begin{array}{l}\text { Removal of the unit addressing optical fiber } \\
\text { characteristics (acceptance angle, numerical } \\
\text { aperture, core, and cladding design). }\end{array}$ & $\begin{array}{l}\text { The unit was considered not fully suitable for students' } \\
\text { target age (13-14 years old). }\end{array}$ \\
\hline ICT & $\begin{array}{l}\text { Introduction of applets for modeling the human } \\
\text { vision mechanism. }\end{array}$ & $\begin{array}{l}\text { To address image formation and students' alternative } \\
\text { conceptions about vision. }\end{array}$ \\
\hline Other aspects & $\begin{array}{l}\text { Introduction of activity addressing measurements } \\
\text { basics. Assessment questions at the end. Use of } \\
\text { additional teaching resources (e.g., photos, figures, } \\
\text { etc). Removal of the initial technological scenario. }\end{array}$ & $\begin{array}{l}\text { Need to tune students' prerequisites with the target } \\
\text { concepts. }\end{array}$ \\
\hline
\end{tabular}


TABLE VI. Analysis of the institutional distance between Italy and Greece.

\begin{tabular}{|c|c|c|c|c|c|}
\hline \multirow[b]{2}{*}{ Dimension } & \multirow[b]{2}{*}{ Feature } & \multicolumn{2}{|c|}{ Range of variability } & \multirow[b]{2}{*}{ Score } & \multirow{2}{*}{$\begin{array}{l}\text { Intercountry } \\
\text { distance }\end{array}$} \\
\hline & & Italy & Greece & & \\
\hline \multirow[t]{5}{*}{ Regulatory } & $\begin{array}{l}\text { 1. Degree of freedom left to teachers to deviate } \\
\text { from national curriculum. }\end{array}$ & Moderate & Scarce & 0 & 0.4 \\
\hline & $\begin{array}{l}\text { 2. Degree of integration across science and } \\
\text { technology subjects. }\end{array}$ & Mostly separated & Mostly separated & 1 & \\
\hline & 3. Degree of integration across science subjects. & Mostly separated & Mostly separated & 1 & \\
\hline & 4. Sequence of contents. & Suggested & Mandatory & 0 & \\
\hline & 5. Use of standardized tests. & Yes & No & 0 & \\
\hline \multirow[t]{5}{*}{ Cognitive } & $\begin{array}{l}\text { 6. Implementation of inquiry-based methods } \\
\text { and student-centered approaches. }\end{array}$ & Scarcely diffused & Scarcely diffused & 1 & 1 \\
\hline & 7. Use of computer-based activities. & Partly frequent & Partly frequent & 1 & \\
\hline & 8. Use of laboratory-based activities. & Partly frequent & Partly frequent & 1 & \\
\hline & 9. Use of modeling approach. & Partly frequent & Partly frequent & 1 & \\
\hline & 10. Use of textbooks. & Frequent & Frequent & 1 & \\
\hline \multirow[t]{5}{*}{ Normative } & $\begin{array}{l}\text { 11. Teachers' beliefs about teaching and } \\
\text { learning science. }\end{array}$ & Traditional & $\begin{array}{l}\text { Varied but often } \\
\text { traditional }\end{array}$ & 1 & 0.8 \\
\hline & $\begin{array}{l}\text { 12. Teachers' views about goals of school } \\
\text { science education. }\end{array}$ & $\begin{array}{l}\text { Basic ideas/facts of } \\
\text { science }\end{array}$ & $\begin{array}{l}\text { Basic ideas and facts of } \\
\text { science }\end{array}$ & 1 & \\
\hline & $\begin{array}{l}\text { 13. Teachers' views about the role of computer- } \\
\text { based in teaching and learning science. }\end{array}$ & $\begin{array}{l}\text { To barely support to } \\
\text { lesson }\end{array}$ & $\begin{array}{l}\text { To simulate } \\
\text { experiments }\end{array}$ & 0 & \\
\hline & $\begin{array}{l}\text { 14. Teachers' views about the role of laboratory } \\
\text { activities in teaching and learning science. }\end{array}$ & Often confirmatory & Often confirmatory & 1 & \\
\hline & 15. Teachers' views about NOS and NOSI. & Empiricism & Empiricism & 1 & \\
\hline
\end{tabular}

\section{DISCUSSION}

In this section, we resume the main trends emerging from the collected data, according to the two research questions of the study.

RQ1: What were the changes made during the process of transfer in the new context?

\section{A. Transfer of the Greek TLS into the Italian context}

Triangulating the data from the background document, the email exchanges, and the peer study visit reports, the host Italian group judged the Greek TLS rather innovative for the Italian physics syllabus, for at least two reasons: (i) the target topic, heat conduction, is seldom taught in detail; (ii) the core goal of familiarizing students with the link between the macroscopic behavior of materials and their microscopic structure was challenging for the Italian students of the target age (14-15 years old), due to teaching practices that privilege macroscopic phenomenology, especially when addressing heat transfer. The innovative features of the TLS led the Italian group to introduce some changes or adaptations to fit the original TLS into the Italian school contexts. The proposed adaptations or changes were discussed in depth and compared with the designers' intentions. As clearly stated in the analyzed field texts (background documents, emails), some of the modifications were rejected and controversial points were rediscussed to look for a better mutual clarification of the designers' intentions and the aspirations of the host group, when possible. Examples of controversial proposals of changes are the removal of the "design of experiment" activities, the inversion of the sequence "ceramics and metals then insulators and conductors," the inclusion of a mechanical analogue to justify heat transfer in a microscopic model, and the need for a mathematical formalization of the collected experimental evidence about heat conduction. It can be inferred that the most effective mechanism in the adaptation of the TLS was the study visit, since it gave the Greek partner the opportunity to gather evidence about the host educational context. After the analysis of the final accepted changes (Table IV), the original designers realized that the transferred version of the TLS had kept certain essential features of the initial core: in particular, the use of (i) a guided inquiry approach, (ii) the POE strategy, (iii) a combination of virtual and hands-on experiments, (iv) the ICT-enhanced visualizations of adapted microscopic model of heat conduction and their relation to macroscopic heat conduction phenomena, and (v) the basic concepts and the relationships between them. The adaptation of the overall conceptual sequence and the introduction of more quantitative aspects, carried out to better fit the original TLS to the local curriculum, were considered to have not affected the core elements. 


\section{B. Transfer of the Italian TLS into the Greek context}

The triangulation of the background document and peer study visit report data suggest that also the Italian TLS was innovative for the target Greek physics syllabus (13-14 years old students) in at least two important aspects: (i) the TLS focused on the interplay between scientific and technological features of optical fibers, while, in the host context, the optical fibers are treated only as applications of geometric optics, (ii) the TLS used a descriptive modeling approach, which privileges data collection and analysis and the construction of some sort of mathematical model; in the Greek science syllabus for the target students, not enough emphasis is given to measurement and treatment of uncertainties, while a more theoretical, interpretative modeling approach is generally implemented. Hence, also for the transfer of this TLS, the host local working group proposed changes (Table V) aimed at introducing the TLS activities in extracurricular time, since the deepening of innovative contents is allowed only in a specific but limited amount of time during a school year. The Italian designers accepted most of these changes, since the main aim was to facilitate the implementation in the Greek school practice. In particular, the changes in the pedagogical approach (use of the POE strategy) and in the sequence (reflection before refraction, measurement theory) were considered as changes that improved the core of the TLS. Similarly, some of the proposed changes improved the modeling approach of the original TLS. The choice of introducing the Fermat principle and the mechanical analogue of the refraction phenomenon was at first considered as a transformation that could impact on the innovative nature of the TLS. However, negotiations between the local working groups led to the acceptance of such changes and the acknowledgment that they could improve the TLS approach. The suppression of the optical fibers scenario weakened, but not diminished, the science and technology interplay that was present in the original TLS. Therefore, while the original TLS was adapted in many ways to fit the Greek context, also such changes were considered to have not affected the TLS core elements.

Overall, triangulating the data from both transfers, we can infer that the implementation of the TLS in the host context was the most effective instrument to reach consensus between the two groups about the changes to adopt in order to facilitate the transfer of the TLS. The peer study visits helped fill the gaps in the previous communication and clarify issues raised by the reading of the background documents. For example, the relevance of the relationships between the macroscopic behavior of heat conductors and microscopic models were clearer to the Italian group only after the second study visit when the Greek TLS was implemented in the Italian context. Similarly, also the time management to address prerequisites, the assessment of tasks about the planning of an experiment and the control of variables; and the bottom-up approach to modeling, were mutually clarified during the peer study visit. This evidence confirms previous findings in business literature [27] about the importance of negotiating different viewpoints through face-to-face exchange and communication between the partners, sharing and explicating a tacit knowledge $[25,46,65,66]$.

\section{RQ2: What were the similarities or differences between} the national curricula and contexts that influenced the process of transfer of an original TLS to the new context?

From the collected evidence, we infer that all three dimensions of the institutional distance between Greek and Italian context played a crucial role in the transfer process. For instance, in the case of the transfer of the conductivity TLS in Italian practice, both the similarities and differences between the Greek and Italian educational systems in the regulatory dimension facilitated the process. For instance, the freedom Italian teachers have for including new topics related to those suggested in the national syllabus seems to have played an important role in the transfer process. In particular, Italian teachers implemented the adapted Greek TLS within school time, not requiring any extracurricular involvement of students and of the teacher who implemented the activities. Second, the circumstance that in both systems, at the lower secondary school level, physics is taught as a single subject clearly helped the implementation of the original TLS hands-on activities on basic thermal conductivity phenomena. Likewise, also the similarities in the cognitive dimension, namely, the predominant transmissive teaching approach based on textbooks, and the weak orientation toward authentic scientific inquiry, have plausibly helped the transfer process. Hence, the host LWG did not need to heavily adapt the proposed activities to the conditions of Italian teaching practice, since the original TLS designers had already taken into account very similar boundary conditions.

The transfer process of the Italian TLS about optical properties of materials was slightly more difficult mainly because of the differences between the two educational systems in the regulatory dimension. Such differences concerned the different types of schools-compulsory general education vs technical education, the lower age of targeted students, and, more importantly, the scarce flexibility of the Greek syllabus in including new topics. Such dearth of flexibility also forced the host Greek partner to include new topics (e.g., the Fermat principle), to change the proposed activity sequence, and to eliminate some activities (e.g., the initial scenario). In such a way, the regulatory dimension improved some parts of the TLSs but, at the same time, it also smoothed some of the innovative characteristics of the TLS, as the reconstruction of the content carried out by the Italian group in the original TLS with the aim of integrating science and technology. Furthermore, the differences in the cognitive and normative 
dimensions played a more relevant role than similarities. For instance, while the modeling approach is partly frequent in the two contexts (see Table VI), the way in which such an approach is implemented in the two contexts (more descriptive in Italy, more interpretative in Greece) has lead to a revision of the activities with the inclusion of a more exploratory modeling approach based on the ray model in geometrical optics.

\section{CONCLUSIONS AND IMPLICATIONS}

Transnational knowledge transfer has been studied in management and business literature for more than twenty years [6,20,28,67-69]. More recently, knowledge transfer between different national contexts has become an important goal also of science education, in light of curriculum reforms worldwide. In particular, the transfer of successful educational practices between different countries has been often advocated in several documents of European policy [2]. However, the issue of how to improve widespread adoption or adaption of researchbased instructional practices and curricula has not been studied in depth at the educational research level [70-72]. The case of inquiry-based approaches is emblematic of this trend, at least in Europe. Actually, enormous financial effort has been put in the last decade in several cross-national projects that informed the EU political willingness to encourage and spread the use of inquiry. However, to this day, we still have only a fragmented evidence about the impact of these projects on the classroom practice in different European countries [73]. To this aim, we have chosen to qualitatively describe and analyze the transfer of two TLSs between two transnational educational contexts, the Greek and Italian one. We consider that one advantage of our approach is that the TLS by their nature are well searched and empirically validated materials, thus facilitating the transparency and mutual understanding by the involved researchers of their objectives, structures, and educational effect.

In the present paper, we have described and analyzed an example of transfer from the point of view of two wellexperienced science education research groups, illustrating strengths and weaknesses of the process. To this aim, we envisioned and applied a multilevel research approach based on a retrospective viewpoint to investigate field texts produced during the process. Subsequently, we built a narrative of personal accounts taking into account different contextual aspects like the national curricula and educational practices in Italy and Greece. To avoid typical pitfalls of self-reported case studies, we used a rigorous content analysis of the field texts, triangulating the collected data obtained using different sources including reports of in situ observations and mutual visits. Moreover, we also carried out a content analysis of the TLSs and of the educational contexts to provide a link between our personal experience and more general issues related to the two educational contexts.

We consider that presentation of a concise approach and the ensuing results of the transfer process was facilitated by choosing a specific relevant model. In our case, the transfer process was modeled by the adaptation and reinvention model of knowledge transfer [45], which led to identify a set of core aspects of the two original TLSs by means of a decontextualization procedure carried out by the designers of the TLSs. Analysis of the changes proposed by the host researchers to recontextualize the TLS in their own context led to a kind of evaluation of the transfer process by looking into how the core aspects were changed in the recontextualization process.

One important contribution of this paper to the field consists of showing how the ARI model may help identifying the key factors that can influence the effectiveness of the transfer process. In particular, the concept and, subsequently, the distinction between core and adapted aspects through the ARI model, may help identifying critical factors that come at play during the transfer process of a TLS. The involved researchers and teachers can hence access to important guidelines to deal with the intrinsic complexity of such complex endeavor, either at the national or cross-national level.

Clearly, such a process should also take into account the cultural differences between the two educational contexts across which the transfer knowledge should take place. To this aim, the degree to which the two educational contexts could be considered "similar" was evaluated using the institutional distance construct [10]. This construct essentially allowed us to identify possible factors that have favored or hindered the transfer process. The construct may also help foresee difficulties and drawbacks when transferring a TLS in two different national contexts and adds value to the use of the ARI model. Our analysis shows that the Greek and Italian educational contexts are substantially similar in two dimensions of the construct (cognitive and normative) and partially similar also in the first dimension (regulatory). Hence, both the transfer of the TLS about thermal conductivity between Greece toward Italy and the transfer of the TLS about optical properties of materials from Italy toward Greece were substantially successful. The relatively more successful transfer was that of the Greek TLS into Italian context. The reason is that the then new introduced policies of the Italy Ministry of Education encouraged the teachers to select and to some extent construct their own sequence of contents to help students achieve more transversal competencies tested at a national level by a standardized assessment examination. The successful transfer of the Greek TLS into the Italian context was also favored by the short distance in the cognitive and normative dimensions (for instance, the scarce diffusion of inquiry-based teaching approaches). Such short distance, however, was not a sufficient condition to fully support also 
the transfer of the Italian TLS into the Greek context. Actually, the differences in the regulatory dimension, namely the limited possibility to include new sequence of contents and new approaches in the Greek curriculum, the lower age of the students and the different type of schools, i.e., compulsory general education instead of technical education, led to a partial adoption of the core elements of the Italian TLS.

Three main implications, which we consider that hold also for knowledge transfer within the same country or across school districts with different educational contexts, can be drawn from our study. The first concerns transfer processes when the designer and host context can engage in direct communication and exchange of information. This may be the case of national or international projects set up to pilot the adoption of innovative TLSs or entire curricula developed in specific contexts. These processes necessarily entail high levels of coordination, collaboration, and communication between the developers and host contexts, for which the example described in this study can be representative of the processes to undertake to make the transfer successful. In particular, the in presence, direct communication, and interactions between the two local working groups and the external expert were by several means crucial in mutually clarifying designers' intentions and host aspirations, enhancing the fidelity of the whole transfer process in terms of the adoption and reinvention model. The mutual constructive communication provided also a useful feedback to the designers about what were the main strengths and the weaknesses related to contents addressed, adopted approaches, proposed sequence of activities. Such feedback was then used to significantly improve also the original TLS back in the original context. Hence, the transfer process has the potentiality of being a powerful way to further improve the design of TLSs as well as research based curricula materials. Correspondingly, during the study visits, the host partner received useful comments about the introduced changes resulting in the reconsideration of some of them, so to preserve original TLS core aspects, which otherwise would have been significantly affected. This finding, which places emphasis on the role of partnerships between the actors involved in the transfer process, confirms previous research results in management literature about knowledge exchange across different countries [20,67]. At this level of national and transnational transfer of educational practices, policy guidelines within EU, until now, have not put enough emphasis on how partnership and networking may favour the transfer process, leaving it almost implicit, in agreement with the principle of "soft governance" in education in Europe [73]. We believe that the transfer of the Greek and Italian TLSs is a representative counterexample to those conventional guidelines which tacitly assume an a priori adoption and adaptation of innovations without any coordination between designer and host contexts. Evidence from international business and management organizational practices indicates that the results obtained in this study are not atypical and may be extended to education through further work that focuses on this issue.

As a second implication, the example of transfer described in this study speaks also about processes of adoption and adaptation in the transfer of educational practices at national or local levels where the level of coordination between designer and host context is not easy to establish or cannot be established at all for several reasons. In particular, the structure of the original TLSs, which provided a clearly identifiable core and a set of noncore resources, was an important factor to favorably implement the transfer process because it helped bootstrap the designer-host partner interaction. As suggested by Varpio et al. [31] (p. 365), "descriptions of educational innovations might helpfully include analyses of the principles upon which they rely." Therefore, as an extension of previous research results, this study suggests that, for setting up a successful transfer process, it is essential that the "core" elements of a TLS be explicitly stated in a synthetic format (for instance, content structure, pedagogy, key ideas, ICT and other resources, important learning objectives, etc.). As shown by our data, the "core" of a TLS may be changed, but if too many core elements are changed the transferred sequence may substantially depart from the intentions of the original designers. Hence, following also results from business field [74] and fidelity of implementation research [41], we explicitly warn to refrain from significant adaptations of a TLS core. We consider that more research is needed to investigate the extent to which the necessary balance between original designers' intentions and host context adaptations of the core of a TLS is successful from the viewpoint of students' learning outcomes. To the same concern, our results may also add to research studies about fidelity of implementation [44]. While it is well known that curriculum materials should include the rationale underlying their design to help teacher better understand designers' recommendations [75], our study suggests the designers should make explicit reference also to those learning activities, procedures and goals that can be changed in the enactment in order for the TLS or curriculum to be more responsive of the students' needs.

While communicating the core elements of a TLS is essential for establishing a potentially effective transfer process, a TLS is not constituted only by its core: specific teaching activities (for instance, certain experiments and simulations) and material resources (namely, teacher's notes, students' worksheets, assessment tasks) are also important features of a TLS. These features should be designed so that they can be adapted in ways the host group consider necessary for a successful transfer. Therefore, also these resources should be clearly indicated and provided to the groups willing to adapt the TLS in a new context. However, also changes to noncore resources may affect 
designers' intentions. In particular, a host group may attempt to shorten the transfer process by introducing major modifications to a non-core TLS feature, for instance, deleting a basic experimental activity, because it is believed that such removal can speed up the adoption of the TLS in their educational context. Not only does this seem to be a decision that may critically affect the designers' intention, but the pattern of results obtained after implementing the modified TLS may concur to contradictory evidence about the effectiveness of the TLS. While we firmly do not advocate the use of "copy exact" policies in educational transfer processes, as it happens in technology [76] or business transfers [36], to presumptively adapt TLS noncore features, is clearly different from the will to embark into a thoughtful and successful transfer process. Our study suggests that there is no short-cut approach to address the diversity between designer and host context. According to our results, to simply adopt successful examples and forcing them to fit their own context in the attempt to be responsive to local institutions guidelines, or to quickly deal with local pressure for introducing innovations, seems highly ineffective. In particular, research in franchise business suggests that "to presumptively adapting a practice to fit a particular environment may be counterproductive when transferring an insufficiently understood practice across borders" [36] (p. 254).

A third aspect, which also deserves further investigation, is that related to the languages of the original designer and the host partner. This issue applies for international transfer and is well known in management and business literature [27]. In the transfer process here discussed, the groups had to deal with two initial different languages, Greek and Italian, and with a third language, English, necessary for discussing about the changes introduced in the adapted TLS and for communicating in presence and online. Therefore, nuances related to the meaning of terms in each of the involved languages should be seriously taken into account when planning the transfer of the TLS so to reduce possible problems in the communication between the designers and the host partners.

Finally, we acknowledge that our results are limited to two TLSs in two specific areas (thermodynamics and optics) of the physics syllabus. Future research studies should aim to achieve a broader coverage of topics.
Further research is also warranted to investigate if the ARI model is applicable to more general curriculum transfer across and within countries, so to provide scholars with more examples that can add to the field of knowledge transfer process.

In conclusion, the study reported here may contribute to science education research as a first attempt at providing evidence-based insights about the process of transfer of effective and successful educational practices across different European countries. To answer our research questions, we built on existing models drawn from business literature. While knowledge transfer in education and in corporate business are clearly different, we believe that further efforts are needed to verify the extent to which the science education research community may maximize the benefit from the knowledge gained from almost thirty years by business and management research on this matter. Recent trends in the latest field, for instance, suggest going beyond a model of adaptation of marketing strategies to foreign local constraints [28] by adopting a creative approach in which the host context is also changed so as to fit the original strategy. While a radical change of a national educational context would be almost impossible and not desirable for political, historical, and economic reasons, some aspects that may decrease the institutional distance between two countries can gradually be introduced on the basis of partnership agreement between countries and taking into account values and aspirations of the national systems as well as of teachers, as the involved professionals. Such a process may be facilitated by specific exchanges like the present ones.

\section{ACKNOWLEDGMENTS}

The work presented in this paper was supported by the European Union through the European Commission Directorate-General for Research and Innovation in the project Materials Science-University-School Partnerships for the Design and Implementation of Research-Based ICT-Enhanced Modules on Material Properties, Science and Society Programme, FP6, SAS6-CT-2006-042942. The authors want to thank Professor M. Meheut, late Professor G. Monroy, and E. Sassi for their contributions during the different phases of the transfer process.
[1] EACEA/Eurydice, Science education in Europe: National policies, practices, and research (European Commission, Brussels, 2011). Retrieved on-line September 2020, https://op.europa.eu/en/publication-detail/-/publication/ bae53054-c26c-4c9f-8366-5f95e2187634/language-en/ format-PDF/source-search.
[2] M. Rocard, Science education NOW: A renewed Pedagogy for the future of Europe (European Commission, Brussels, 2007). Retrieved from: https://ec.europa.eu/research/ science-society/document_library/pdf_06/report-rocardon-science-education_en.pdf. 
[3] E. D. Darr and T.R. Kurtzberg, An investigation of partner similarity dimensions on knowledge transfer, Org. Behav. Human Dec. Proc. 82, 28 (2000).

[4] M. Song, H. Berends, H. van der Bij, and M. Weggeman, The effect of IT and co-location on knowledge dissemination, J. Prod. Innov. Mng. 24, 52 (2007).

[5] S. G. Goh, Managing effective knowledge transfer: An integrative framework and some practice implications, J. Know. Mng. 6, 23 (2002).

[6] G. Szulanski, Exploring internal stickiness: Impediments to the transfer of best practice within the firm, Strat. Mng. J. 17, 27 (1996).

[7] R. R. Nelson and S. G. Winter, Toward an evolutionary theory of economic capabilities, Am. Econ. Rev. 63, 440 (1973).

[8] D. J. Teece, Technology transfer by multinational firms: The resource cost of transferring technological know-how, Econ. J. 87, 242 (1977).

[9] B. Kogut and U. Zander, Knowledge of the firm and the evolutionary theory of the multinational corporation, J. Intl. Bus. Stud. 24, 625 (1993).

[10] T. Kostova, Transnational transfer of strategic organizational practices: A contextual perspective, Acad. Mng. Rev. 24, 308 (1999).

[11] A. Spyrtou, J. Lavonen, A. Zoupidis, A. Loukomies, D. Pnevmatikos, K. Juuti, and P. Kariotoglou, Transferring a teaching learning sequence between two different educational contexts: The case of Greece and Finland, Int. J. Sci. Math. Educ. 16, 443 (2017).

[12] M. Méheut and D. Psillos, Teaching-learning sequences: Aims and tools for science education research, Int. J. Sci. Educ. 26, 515 (2004).

[13] J. Guisasola, Z. Kristina, I. Jaume Ametller, and I. Gutierrez-Berraondo, Evaluating and redesigning teaching learning sequences at the introductory physics level, Phys. Rev. Phys. Educ. Res. 13, 020139 (2017).

[14] D. Psillos and P. Kariotoglou, Theoretical issues related to designing and developing teaching-learning sequences in Iterative Design of Teaching-Learning Sequences, edited by D. Psillos and P. Kariotoglou (Springer Science and Business Media, Dordrecht, 2016), pp. 11-34.

[15] D. Psillos, A. Molohidis, M. Kallery, and E. Hatzikraniotis, The iterative evolution of a teaching- learning sequence on the thermal conductivity of materials in Iterative Design of Teaching-Learning Sequences, edited by D. Psillos and P. Kariotoglou (Springer Science and Business Media, Dordrecht, 2016), pp. 287-329.

[16] I. Testa and G. Monroy, The iterative design of a teachinglearning sequence on optical properties of materials to integrate science and technology in Iterative Design of Teaching-Learning Sequences, edited by D. Psillos and P. Kariotoglou (Springer Science and Business Media, Dordrecht, 2016), pp. 233-286.

[17] L. Borghi, A. De Ambrosis, and P. Mascheretti, Microscopic models for bridging electrostatics and currents, Phys. Educ. 42, 146 (2007).

[18] J. Guisasola, J. M. Almudi, M. Ceberio, and J. L. Zubimendi, Designing and evaluating research-based instructional sequences for introducing magnetic fields, Int. J. Sci. Math. Educ. 7, 699 (2008).

[19] N. Papadouris and C. Constantinou, Investigating middle school students' ability to develop energy as a framework for analyzing simple physical phenomena, J. Res. Sci. Teach. 53, 119 (2016).

[20] Y. Duan, W. Nie, and E. Coakes, Identifying key factors affecting transnational knowledge transfer, Inf. Mng. 47, 356 (2010).

[21] A.C. Inkpen and A. Dinur, Knowledge management processes and international joint ventures, Organ. Sci. 9, 454 (1998).

[22] A. K. Gupta and V. Govindarajan, Knowledge flows within multinational corporations, Strat. Mgmt. J. 21, 473 (2000).

[23] I. Nonaka, A dynamic theory of organizational knowledge creation, Organ. Sci. 5, 14 (1994).

[24] D. A. Jankowicz, Planting a paradigm in central Europe: Do we graft, or must we breed the rootstock anew?, Mng. Learn. 30, 281 (1999).

[25] P. Almeida and R. Grant, International Corporations and Cross-Border Knowledge Transfer in the Semiconductor Industry (Carnegie Bosch Institute for Applied Studies in International Management, Pittsburgh, Pa, 1998). Retrieved on-line September $2020 \mathrm{https}: / /$ web.archive.org/web/ 20011011182535/http://cbi.gsia.cmu.edu:80/newweb/ 1998WorkingPapers/grant/Almeida.html.

[26] C. A. Bartlett and S. Ghoshal, Managing across Borders: The Transnational Solution (Harvard Business School Press, Boston, MA, 1989).

[27] J. M. Hurt and S. Hurt, Transfer of managerial practices by French food retailers to operations in Poland, Acad. Mng. Exec. 19, 36 (2005).

[28] A. Yakhlef, Knowledge transfer as the transformation of context, J. High Techn. Mng. Res. 18, 43 (2007).

[29] D. Berliner, Educational research: The hardest science of them all, Educ. Res. 31, 18 (2002).

[30] P. Haidet, P. A. Kelly, S. Bentley, B. Blatt, C. L. Chou, A. H. Fortin et al. Not the same everywhere. Patientcentered learning environments at nine medical schools, J. Gen. Internal Medicine 21, 405 (2006).

[31] L. Varpio, R. Bell, G. Hollingworth et al. Is transferring an educational innovation actually a process of transformation?, Adv. Heal. Sci Educ. 17, 357 (2012).

[32] Y. Kanu, Tensions and dilemmas of cross-cultural transfer of knowledge: Post-structural/postcolonial reflections on an innovative teacher education in Pakistan, Int. J. Educ. Dev. 25, 493 (2005).

[33] J. M. Beyer, D. P. Ashmos, and R. Osborn, Contrasts in enacting TQM: Mechanistic vs. organic ideology and implementation, J. Qual. Mng. 2, 3 (1997).

[34] P. J. Lane, J. E. Salk, and M. A. Lyles, Absorptive capacity, learning, and performance in international joint ventures, Strat. Mgmt. J. 22, 1139 (2001).

[35] B. Simonin, Transfer of marketing know-how in international strategic alliances: An empirical investigation of the role and antecedents of knowledge ambiguity, J. Int. Bus. Stud. 30, 463 (1999).

[36] G. Szulanski and R. J. Jensen, Presumptive adaptation and the effectiveness of knowledge transfer, Strat. Mgmt. J. 27, 937 (2006). 
[37] R. Pinto, Introducing curriculum innovations in science: Identifying teachers' transformations and the design of related teacher education, Sci. Educ. 89, 1 (2005).

[38] A. Zappia, G. Capasso, S. Galano, I. Marzoli, L. Smaldone, and I. Testa, Investigating science teachers' transformations of inquiry aspects when implementing research-based teaching-learning sequences, in Cognitive and Affective Aspects in Science Education Research, edited by K. Hahl, K. Juuti, J. Lampiselkä, A. Uitto, and J. Lavonen (Springer Dordrecht, 2017), pp. 279-293.

[39] L. M. Desimone and K. L. Hill, Inside the black box: Examining mediators and moderators of a middle school science invention, Educ. Eval. Policy Anal. 39, 511 (2017).

[40] C. J. Harris, W. R. Penuel, C. M. D'Angelo, A. H. DeBarger, L. P. Gallagher, C. A. Kennedy, and J.S. Krajcik, Impact of project-based curriculum materials on student learning in science: Results of a randomized controlled trial, J. Res. Sci. Teach. 52, 1362 (2015).

[41] Y.-J. Lee and S. Chue, The value of fidelity of implementation criteria to evaluate school based science curriculum innovations, Int. J. Sci. Educ. 35, 2508 (2013).

[42] C. O'Donnell, Defining, conceptualizing, and measuring fidelity of implementation and its relationship to outcomes in K-12 curriculum intervention research, Rev. Educ. Res. 78, 33 (2008).

[43] O. Lee, R. Penfield, and J. Maerten-Rivera, Effects of fidelity of implementation on science achievement gains among English language learners, J. Res. Sci. Teach. 46, 836 (2009).

[44] K. L. McNeill, L. M. Marco-Bujosa, M. GonzálezHoward, and S. Loper, Teachers' enactments of curriculum: Fidelity to procedure versus fidelity to goal for scientific argumentation, Int. J. Sci. Educ. 40, 1455 (2018).

[45] E. M. Rogers, Diffusion of Innovations, 5th ed. (Free Press, New York, NY, 2003).

[46] H. Bresman, J. Birkinshaw, and R. Nobel, Knowledge transfer in international acquisitions, J. Int. Bus. Stud. 30, 439 (1999).

[47] R. Duit, H. Gropengieber, U. Kattmann, M. Komorek, and I. Parchmann, The model of educational reconstructionA framework for improving teaching and learning science, in Science Education Research and Practice in Europe Retrospective and Prospective, edited by D. Jorde and J. Dillon (Sense Publishers Research and Development in Science Education, Rotterdam, 2012), pp. 13-37.

[48] R. Duit, H. Gropengießer, and U. Kattmann, Towards science education research that is relevant for improving practice: The model of educational reconstruction, in Developing Standards in Research on Science Education, edited by H. E. Fischer (Taylor and Francis, London, 2005), pp. 1-9.

[49] See Supplemental Material at http://link.aps.org/ supplemental/10.1103/PhysRevPhysEducRes.16.020146 for the relevant literature on which the TLSs were developed (A1 and A2), the description of the adapted TLSs (B), the description of the TLSs activities (C1 and C2), the description of the assessment tools (D1 and D2), the excerpts from background documents (E1, E2, F1, and F2), the excerpts from peer study visit reports (G1 and G2).
[50] Hatzikraniotis E, M. Kallery, T. Molohidis, and D. Psillos, Students' design of experiments: An inquiry module on the conduction of heat, Phys. Educ. 45, 335 (2010).

[51] R. White and R. Gunstone, Probing Understanding (Routledge, Milton Park, 1992).

[52] I. Testa, S. Lombardi, G. Monroy, and E. Sassi, An innovative context-based module to introduce students to the optical properties of materials, Phys. Educ. 46, 167 (2011).

[53] Cabri software is developed and distributed by the Cabrilog company, https://www.cabri.com/en/student/cabri-ii-plus/.

[54] D. J. Clandinin and F. M. Connelly, Narrative Inquiry: Experience and Story in Qualitative Research (JosseyBass, San Francisco, 2000).

[55] R. K. Yin, Case Study Research: Design and Methods (Sage, Thousand Oaks, CA, 2013).

[56] K. Krippendorf, Content Analysis: An Introduction to its Methodology, 4th ed. (Sage, Beverly Hills, CA, 2004).

[57] H.-F. Hsieh and S. Shannon, Three approaches to qualitative content analysis, Qualitative health research 15, 1277 (2005).

[58] Z. Yang, C. Su, and K. S. Fam, Dealing with institutional distances in international marketing channels: Governance strategies that engender legitimacy and efficiency, J. Market. 76, 41 (2012).

[59] H. Jansson and S. Sandberg, Internationalization of small and medium sized enterprises in the Baltic Sea Region, J. Int. Mng. 14, 65 (2008).

[60] D. $\mathrm{Xu}$ and O. Shenkar, Institutional distance and the multinational enterprise, Acad. Mng. Rev. 27, 608 (2002).

[61] L. Eden and S. Miller, Distance matters: Liability of foreignness, institutional distance and ownership strategy. Adv. Int. Mng. 16, 187 (2004).

[62] R. Scott, Institutions and Organizations (Sage, Thousand Oaks, CA, 1995).

[63] M. Berger and T. Luckman, The Social Construction of Reality (Penguin, Harmondsworth, UK, 1967).

[64] S. Estrin, D. Ionascu, and K. Meyer, Formal and Informal Institutional Distance, and International Entry Strategies, William Davidson Working Paper No. 728 (2007).

[65] J. Mohr and R. Spekman, Characteristics of partnership success: Partnership attributes, communication behavior, and conflict resolution techniques, Strat. Mng. J. 15, 135 (1994).

[66] W. Danis and A. Parkhe, Hungarian-western partnerships: A grounded theoretical model of integration processes and outcomes, J. Int. Bus. Stud. 33, 423 (2002).

[67] R. S. Bhagat, B. L. Kedia, P. D. Harveston, and H. C. Triandis, Cultural variations in the cross-border transfer of organizational knowledge: An integrative framework, Acad. Mng. Rev. 27, 204 (2002).

[68] S. Chen, Y. Duan, J. S. Edwards, and B. Lehaney, Toward understanding inter-organizational knowledge transfer needs in SMEs: insight from a UK investigation, J. Know. Mng. 10, 6 (2006).

[69] S. Chevrier, Cross-cultural management in multinational project groups, J. World Bus. 38, 141 (2003).

[70] J. Zajda, Cultural transferability and cross-cultural textbook development, Educ. Technol. Soc. 22, 83 (2004). 
[71] M. R. Garrison, A qualitative study investigating the processes of educational knowledge transference from the Finnish cultural context, Ph.D. thesis, Evangel University, Springfield, MO, 2019, https://search.proquest .com/docview/2212203545?pq-origsite $=$ gscholar.

[72] A. B. Kayes, D. C. Kayes, and Y. Yamazaki, Transferring knowledge across cultures: A learning competencies approach, Perform. Improv. Q. 18, 87 (2005).

[73] C.-J. Rundgren, Implementation of inquiry-based science education in different countries: Some reflections, Cult. Stud. Sci. Educ. 13, 607 (2018).
[74] J. L. Bradach, Franchise Organizations (Harvard Business School Press Boston, MA, 1998).

[75] E. A. Davis and J. Krajcik, Designing educative curriculum materials to promote teacher learning. Educ. Res. 34, 3 (2005).

[76] C. J. McDonald, The evolution of Intel's copy exactly! Technology transfer method, Intel Tech. J. Q4, https://pdfs .semanticscholar.org/3195/172157973017fe8114e91d20 b52eaf69d12c.pdf. Accessed, 5 September 2019 (1998). 